\title{
On the influence of T-Stress on photoelastic analysis under pure mode II loading
}

\section{Mahnaz Zakeri}

Mechanical Eng. Dep., Iran University of Science and Technology, Narmak, Tehran 16844, Iran

e-mail:m_zakeri@iust.ac.ir

\section{Chiara Colombo}

Politecnico di Milano, Dipartimento di Meccanica, Via la Masa 34, 21058 Milano

e-mail: chiara.colombo@mecc.polimi.it

RIASSUNTO: Dalla definizione classica dello stato di sollecitazione elastica in prossimità dell'apice di una cricca, il termine $\mathrm{T}$ costante nello sviluppo in serie del fattore di intensificazione degli sforzi esiste solo in presenza del modo I di carico. Tuttavia, recenti studi mostrano che il T-stress può esistere anche in condizione di modo II, e modificare significativamente il campo di sforzi elastici presenti nell'intorno dell'apice della cricca. Questi effetti possono essere visualizzati e testati sperimentalmente col metodo della fotoelasticità. In questo lavoro è proposto uno studio sull'influenza del T-stress in cricche sollecitate secondo il modo II e i suoi effetti sul campo di frange visibili sperimentalmente. I provini utilizzati sono dischi, chiamati Brazilian disks, al cui interno sono contenute cricche centrali da analizzare: i risultati sperimentali indicano che questi tipi di provini contengono valori negativi di T-stress. I valori ottenuti sperimentalmente sono poi confrontati con i risultati di simulazioni numeriche. Per meglio interpretare le differenze tra valori sperimentali e numerici, sono inoltre state eseguite analisi FEM 3D: i risultati mostrano l'influenza della reale geometria del fronte sui valori dei fattori di intensificazione degli sforzi.

ABSTRACT. According to the classical definition for in-plane modes of crack deformation, the constant stress term $\mathrm{T}$ exists only in the presence of mode I. However, recent studies show that this term can exist in mode II conditions as well, and significantly affect the elastic stress field around the crack tip. These effects can be visualized using the experimental method of photoelasticity. Based on the analytical studies, presence of the T-stress in mode II cracks transforms the isochromatic fringe patterns from symmetric closed loops to asymmetric and discontinuous shapes. In this paper, presence of the T-stress in mode II cracks and its effects on the fringe patterns is experimentally investigated. The test specimens are Brazilian disks containing very sharp central cracks: experimental results indicate that these specimens contain negative values of T-stress. Experimental values are then compared to numerical results. To better understand the differences between experimental and numerical values, a thee dimensional analysis is performed with the finite element method: results show the influence of the real geometry of the crack front on the stress intensity factors.

KEYWORDS: sharp crack generation, curved crack tip, Brazilian disk specimen, T-stress, mode II loading.

\section{INTRODUCTION}

Many structural materials are subjected to crack forming and propagation during their service life. These cracks influence the stress distribution in the component and can result in significant decrease of its strength. Because of the importance of safety and reliability, the crack problem has been of interest to a large number of researchers. Elastic stress field around a crack tip is usually written as a set of infinite series expansions as [1]:

$$
\begin{aligned}
\sigma_{\mathrm{xx}} & =\frac{\mathrm{K}_{\mathrm{I}}}{\sqrt{2 \pi \mathrm{r}}} \cos \left(\frac{\theta}{2}\right)\left[1-\sin \left(\frac{\theta}{2}\right) \sin \left(\frac{3 \theta}{2}\right)\right] \\
& +\frac{\mathrm{K}_{\mathrm{II}}}{\sqrt{2 \pi \mathrm{r}}} \sin \left(\frac{-\theta}{2}\right)\left[2+\cos \left(\frac{\theta}{2}\right) \cos \left(\frac{3 \theta}{2}\right)\right]+\mathrm{T}+\mathrm{O}\left(\mathrm{r}^{1 / 2}\right) \\
\sigma_{\mathrm{yy}} & =\frac{\mathrm{K}_{\mathrm{I}}}{\sqrt{2 \pi \mathrm{r}}} \cos \left(\frac{\theta}{2}\right)\left[1+\sin \left(\frac{\theta}{2}\right) \sin \left(\frac{3 \theta}{2}\right)\right] \\
& +\frac{\mathrm{K}_{\mathrm{II}}}{\sqrt{2 \pi \mathrm{r}}} \sin \left(\frac{\theta}{2}\right) \cos \left(\frac{\theta}{2}\right) \cos \left(\frac{3 \theta}{2}\right)+\mathrm{O}\left(\mathrm{r}^{1 / 2}\right) \\
\sigma_{\mathrm{xy}}= & \frac{\mathrm{K}_{\mathrm{I}}}{\sqrt{2 \pi \mathrm{r}}} \cos \left(\frac{\theta}{2}\right) \sin \left(\frac{\theta}{2}\right) \sin \left(\frac{3 \theta}{2}\right) \\
+ & \frac{\mathrm{K}_{\mathrm{II}}}{\sqrt{2 \pi \mathrm{r}}} \cos \left(\frac{\theta}{2}\right)\left[1-\sin \left(\frac{\theta}{2}\right) \sin \left(\frac{3 \theta}{2}\right)\right]+\mathrm{O}\left(\mathrm{r}^{1 / 2}\right)
\end{aligned}
$$


where $r$ and $\theta$ are the polar coordinates centred at the crack tip (Fig. 1). The two first terms in each expansion are the singular stresses, depending on the mode I and mode II stress intensity factors $\mathrm{K}_{\mathrm{I}}$ and $\mathrm{K}_{\mathrm{II}}$. The second term, often called the T-stress, is constant and independent of the distance $r$ from the crack tip. The next terms of this expansion, represented by $\mathrm{O}\left(\mathrm{r}^{1 / 2}\right)$, are higher order terms which are usually neglected in the singularity dominated zone.

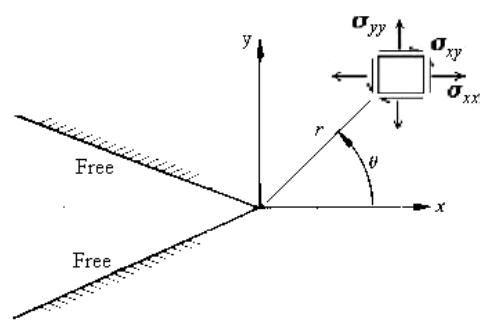

Figure 1. Crack tip coordinates and stress components.

Based on the classical definition of crack deformation modes [1], the T-stress exists only in mode I or combinations of mode I and II, and it vanishes in pure mode II condition. However, some published results of several analytical and numerical researches indicate that this term can also exist in mode II problems [2-4], and ignoring its effect can introduce significant inaccuracies in predicting mode II brittle fracture.

The constant stress term $\mathrm{T}$ acts over a large distance from the crack tip. The amounts of this stress and its sign have an important effect on the brittle fracture of engineering materials, whether in predominantly linear elastic materials or elastic-plastic cases. It has been shown that the sign of T-stress influences the stability and direction of fracture path. Presence of the negative T-stress in mode I leads the crack to grow along its plane, while when the $\mathrm{T}$ is positive, the crack deviates from its initial plane [5]. This effect is not restricted to mode I conditions. Ayatollahi and Abbasi [6] have shown that the T-stress can affect considerably the angle between the crack line and fracture path in mode II as well. Presence of T-stress also affects the mode II fracture toughness. It has been shown that $\mathrm{T}$ is the most important parameter for describing the crack tip constraint in constrained yielding [7]. For mode II specimens exhibiting small to moderate scale yielding around the crack tip, Ayatollahi et al. [8] have shown that $\mathrm{T}$ affects the size and shape of the plastic zone. The stresses inside the plastic zone are also influenced significantly by a remote $\mathrm{T}$-stress. Thus, ignoring the $\mathrm{T}$-term in mode II can introduce considerable inaccuracies in studying of mode II brittle fracture.

Considering this point, the elastic stress components near the crack tip in mode II can be expressed in Cartesian coordinate system as:

$\sigma_{\mathrm{xx}}=\frac{\mathrm{K}_{\mathrm{II}}}{\sqrt{2 \pi \mathrm{r}}} \sin \left(\frac{-\theta}{2}\right)\left[2+\cos \left(\frac{\theta}{2}\right) \cos \left(\frac{3 \theta}{2}\right)\right]+\mathrm{T}+\mathrm{O}\left(\mathrm{r}^{1 / 2}\right)$

$$
\begin{aligned}
& \sigma_{\mathrm{yy}}=\frac{\mathrm{K}_{\mathrm{II}}}{\sqrt{2 \pi \mathrm{r}}} \sin \left(\frac{\theta}{2}\right) \cos \left(\frac{\theta}{2}\right) \cos \left(\frac{3 \theta}{2}\right)+\mathrm{O}\left(\mathrm{r}^{1 / 2}\right) \\
& \sigma_{\mathrm{xy}}=\frac{\mathrm{K}_{\mathrm{II}}}{\sqrt{2 \pi \mathrm{r}}} \cos \left(\frac{\theta}{2}\right)\left[1-\sin \left(\frac{\theta}{2}\right) \sin \left(\frac{3 \theta}{2}\right)\right]+\mathrm{O}\left(\mathrm{r}^{1 / 2}\right)
\end{aligned}
$$

The crack parameters $K_{I I}$ and $T$ in these equations can be determined using different analytical, numerical, and experimental methods. Among the experimental techniques, method of photoelasticity has been frequently used for calculating the crack parameters in various cracked specimens [e.g. 9,10]. Moreover, several procedures have been suggested and utilized to determine $\mathrm{K}_{\mathrm{I}}, \mathrm{K}_{\mathrm{II}}$ and $\mathrm{T}$ from photoelastic fringe patterns.

Using the stress series expansion (Eq. 1) and the fundamental optic equations for an isochromatic fringe [11], in general, a non-linear equation is obtained in terms of three unknown parameters $\mathrm{K}_{\mathrm{I}}, \mathrm{K}_{\mathrm{II}}$, and $\mathrm{T}$. Different methods have been suggested to solve this equation among which, the over- deterministic technique is able to provide a more accurate analysis [11]. Because it is a fullfield method that can use the coordinates $r$ and $\theta$ from four or more arbitrary points on given isochromatic fringes. The resultant non-linear equations are solved numerically, and the fitting process involves both the Newton-Raphson method and the method of least squares. Another full-field technique is proposed by Nurse and Patterson [12], based on complex Fourier analysis which is more complicated.

Although the full-field methods generate solutions with high degree of accuracy for mode I and mixed mode I/II problems, sometimes the results are not satisfactory for pure mode II. On the other hand, the theoretical results suggest that the fringe patterns are always symmetric in mode II conditions [11]. However, asymmetric fringes have been observed in some of the previous experiments [13]. As described by previous researches [2,13], this inconsistency between the theory and experiments can be due to neglecting the effect of T-stress in some mode II specimens.

The main objective of this paper is to investigate the presence of $\mathrm{T}$ in a mode II specimen, and its effects on the isochromatic fringe patterns around the crack tip by using the experimental method of photoelasticity. In the following, a brief review on the analytical relations [13] is presented. Then, different steps of the performed experimental program are described: cracks are created, using a mechanical shock, in sufficiently thick polycarbonate sheets (thickness of $10 \mathrm{~mm}$ ) to avoid problems of buckling in the following loading phase. This process is used to make Brazilian disk specimens containing sharp central cracks, loaded in mode II conditions.

The observed fringe patterns are finally compared with numerical predictions. Also, calculated crack parameters are validated by using results from finite element analysis (FEM). Although the experimental results had a good agreement with FEM, there were some minor errors 
which could be related to the curved shape of the crack front through the specimen thickness. This latter effect is also investigated by using a 3D finite element model. The crack front is assumed to be in a circular arc form; and singular elements around the crack tip are generated by applying the quarter point technique on quadratic 20node elements.

\section{MATHEMATICAL RELATIONS OF ISOCHROMATIC FRINGES}

Based on the classical concepts of photoelasticity, locus of an isochromatic fringe around the crack tip is expressed as [11]:

$2 \tau_{\mathrm{m}}=\frac{\mathrm{Nf}}{\mathrm{h}}$

where $\tau_{\mathrm{m}}$ is maximum in-plane shear stress. $\mathrm{N}$ and $\mathrm{f}$ are the fringe order and material fringe value, respectively, and $\mathrm{h}$ is the thickness of specimen. Also, the maximum shear stress $\tau_{\mathrm{m}}$ is related to the Cartesian stress components with this equation [11]:

$$
\left(2 \tau_{\mathrm{m}}\right)^{2}=\left(\sigma_{\mathrm{xx}}-\sigma_{\mathrm{yy}}\right)^{2}+4 \sigma_{\mathrm{xy}}^{2}
$$

Substituting stress terms from Eqs. $(2,3)$ in Eq. (4), the mathematical equation for a fringe loop developing around a mode II crack tip is written in a simple form presented in ref. [13] and defining three dimensionless parameters:

$\mathrm{S}=\left(\frac{\mathrm{Nf}}{\mathrm{hT}}\right)^{2}, \mathrm{~B}=\frac{\mathrm{T} \sqrt{\pi \mathrm{a}}}{\mathrm{K}_{\mathrm{II}}}, \mathrm{r}^{\prime}=\mathrm{r} / 2 \mathrm{a}$

In which a is the crack length for edge cracks and semi- crack length for central cracks, a quadratic algebraic equation is obtained. Solving this equation, the locus of isochromatic fringes in presence of T-stress is determined as:

$\sqrt{r^{\prime}}=\frac{b \pm \sqrt{b^{2}+(S-1)\left(4-3 \sin ^{2} \theta\right)}}{2 B(1-S)}$

where: $b=\left(\sin \theta \cos \frac{3 \theta}{2}+2 \sin \frac{\theta}{2}\right)$

This equation predicts asymmetric fringes which are not continuous along the crack edges (see Fig. 2-a). Meanwhile, in the case of zero T-stress, the locus of isochromatic fringes is obtained as Eq.(7) that suggests a set of closed loops, symmetric about directions $\theta=0^{\circ}$ and $\theta=$ $90^{\circ}$, similar to the earlier analytical results presented in $[11,14]$. A typical scheme of these loops is shown in Fig. 2.b.

$$
\mathrm{r}=\frac{1}{2 \pi}\left[\frac{\mathrm{hK}}{\mathrm{Nf}}\right]^{2}\left(4-3 \sin ^{2} \theta\right)
$$

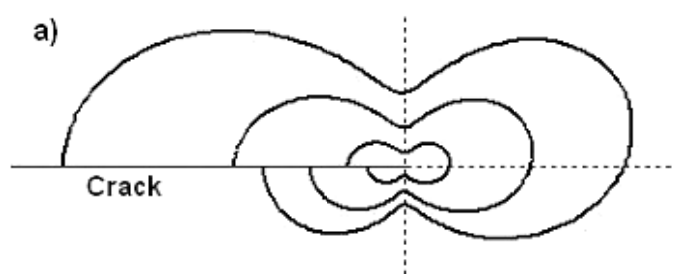

b)

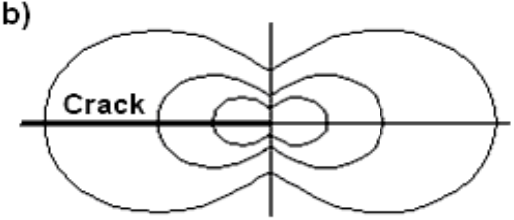

Figure 2. Typical isochromatic fringes around a mode II crack tip: a) $\mathrm{T} \neq 0, \mathrm{~b}) \mathrm{T}=0$.
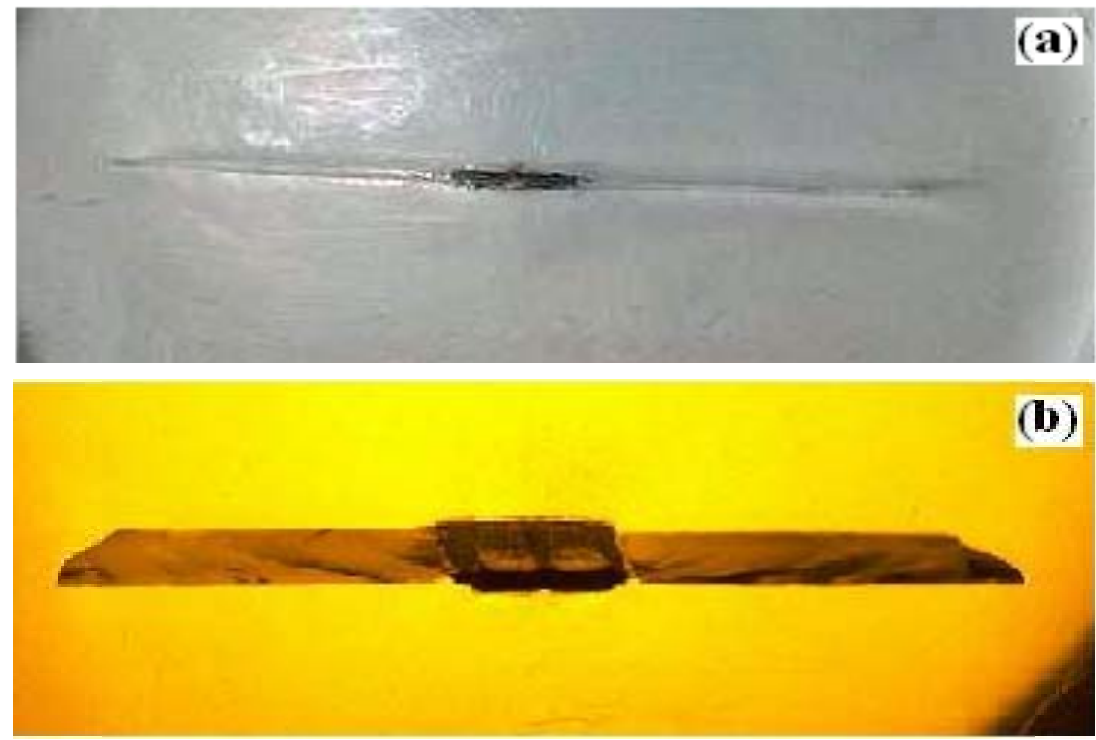

Figure 3. Created semi-natural cracks: a) front view, b) through the sheet thickness. 


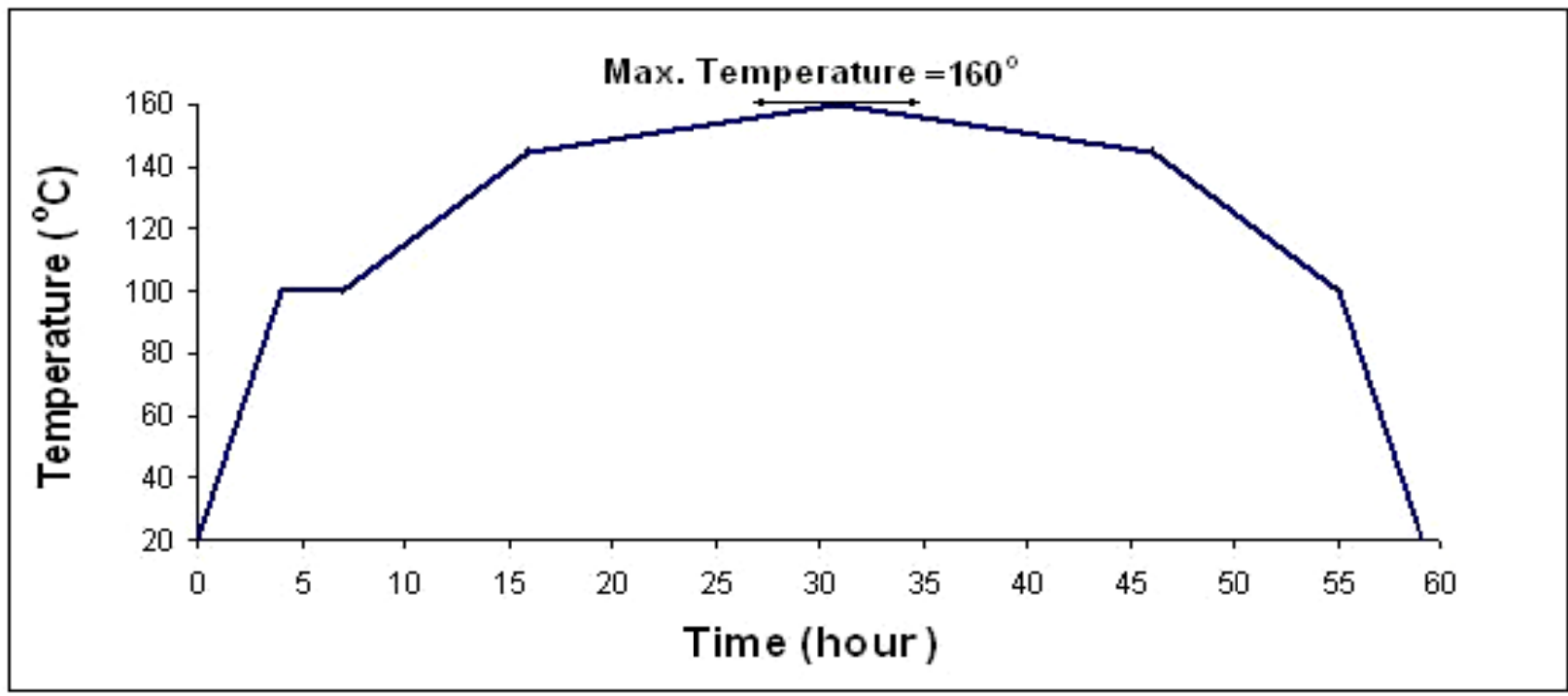

Figure 4. Applied thermal cycle to remove residual stresses from test specimens.

\section{EXPERIMENTAL PROCEDURE}

\subsection{Specimen Preparation}

For experimental investigation of T-stress effects on the elastic stress field, two Brazilian disk specimens were utilized. The disks were made from a polycarbonate sheet of thickness $t=10 \mathrm{~mm}$. For creation of the central cracks, first an initial small notch was made by using the water jet technology. The notched sheet was put in liquid nitrogen of $-196^{\circ} \mathrm{C}$ temperature for 15 minutes in order to become completely brittle, and then the crack was created by applying a mechanical shock on the notched zone. The crack obtained in this way is very close to a natural crack with sharp tips (Fig. 3-a). For the performed tests, the total crack lengths were $2 \mathrm{a}=58.8 \mathrm{~mm}$ and $2 \mathrm{a}=60 \mathrm{~mm}$. Then the sheet was cut in the form of two disks of radius $\mathrm{R}=66.5 \mathrm{~mm}$ (specimen $\mathrm{N}-1$ ) and $\mathrm{R}=60 \mathrm{~mm}$ (specimen $\mathrm{N}$ 2 ), respectively. It is notable that the crack tips generated in this way are not perfectly straight through the thickness, and there is a curvature which may affect the results specially in the case of thick sheets (Fig. 3.b).

Since the specimens should be stress-free before loading, all residual stresses induced during the cracking and cutting process were removed by using a thermal treatment according to Fig. 4. It is seen from the figure that the heating rate is decreased in temperatures higher than $145^{\circ} \mathrm{C}$, which is the minimum glass transition temperature for polycarbonate [15]. The specimens were placed in the furnace for 59 hours and then, stresses were checked in the polariscope machine. It was observed that the disks are almost stress-free.

\subsection{Determination of Material Fringe Value}

As an optical property of photoelastic materials, the fringe value for an intact polycarbonate is about $\mathrm{f}=7$ [N/(mm·fringe)] [11]. Since the specimens were exposed to heat treatment, a material calibration test was per- formed to determine the fringe value after thermal process. For this purpose, a disk of diameter $50 \mathrm{~mm}$ from the same material was put in the furnace along with the main specimens. This disk was then employed for a calibration test under diagonal compressive load according to [16]. Test was conducted in two steps including loading and unloading, and considering both cases, the fringe value was obtained as $\mathrm{f}=6.9[\mathrm{~N} /(\mathrm{mm} \cdot$ fringe $)]$. Fig. 5 shows the isochromatic fringe patterns in the calibration disk when the two fringes of order $\mathrm{N}=8$ are joining together in the centre of disk.

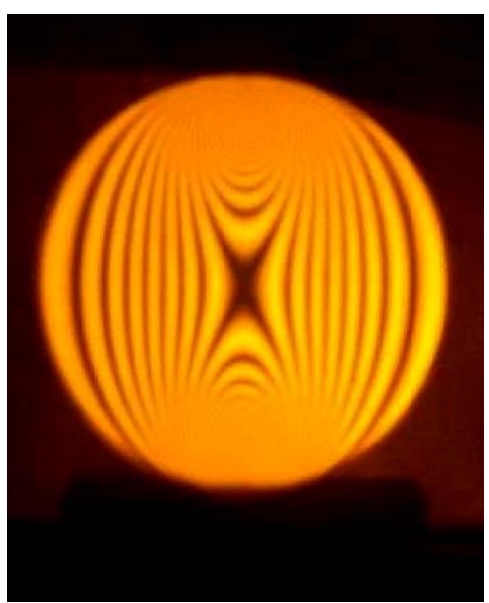

Figure 5. Isochromatic fringes in calibration disk.

\subsection{Photoelastic Tests}

The cracked Brazilian disks were sited in the loading frame as shown in Fig. 6. Compressive loads were applied by using the loading screw and the gage shows the force amount. The loads were selected as $\mathrm{P}=525 \mathrm{~N}$ and $\mathrm{P}=367.5 \mathrm{~N}$ for specimens $\mathrm{N}-1$ and $\mathrm{N}-2$, respectively. It should be mentioned that using the earlier FEM results [4], the angle $\alpha$ between the crack line and loading direction (see Fig. 6) was such selected that the crack was exposed to mode II condition. These angles were $\alpha=24.5^{\circ}$ for $\mathrm{N}-1(\mathrm{a} / \mathrm{R}=0.44)$, and $\alpha=23.2^{\circ}$ for $\mathrm{N}-2(\mathrm{a} / \mathrm{R}=0.5)$. Fig. 7 

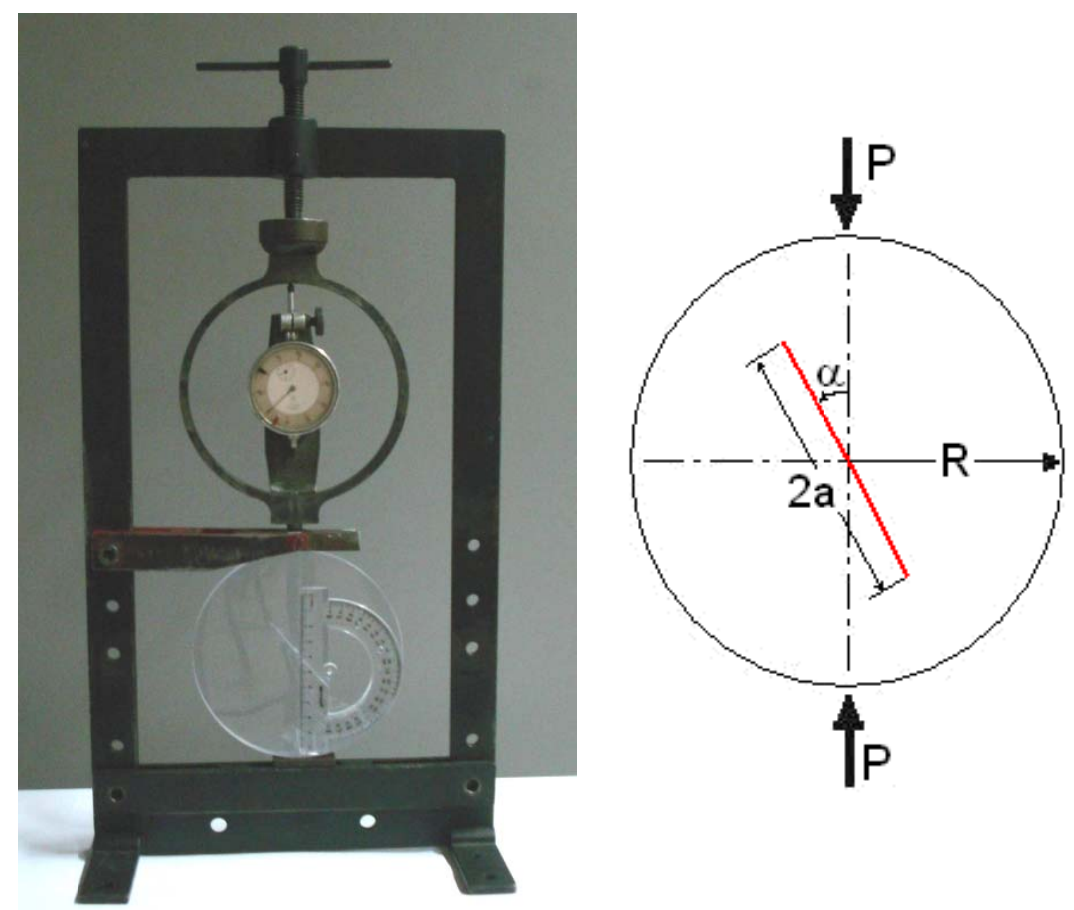

Figure 6. Loading frame employed to apply compressive load on the disks and definition of the characteristic dimensions.
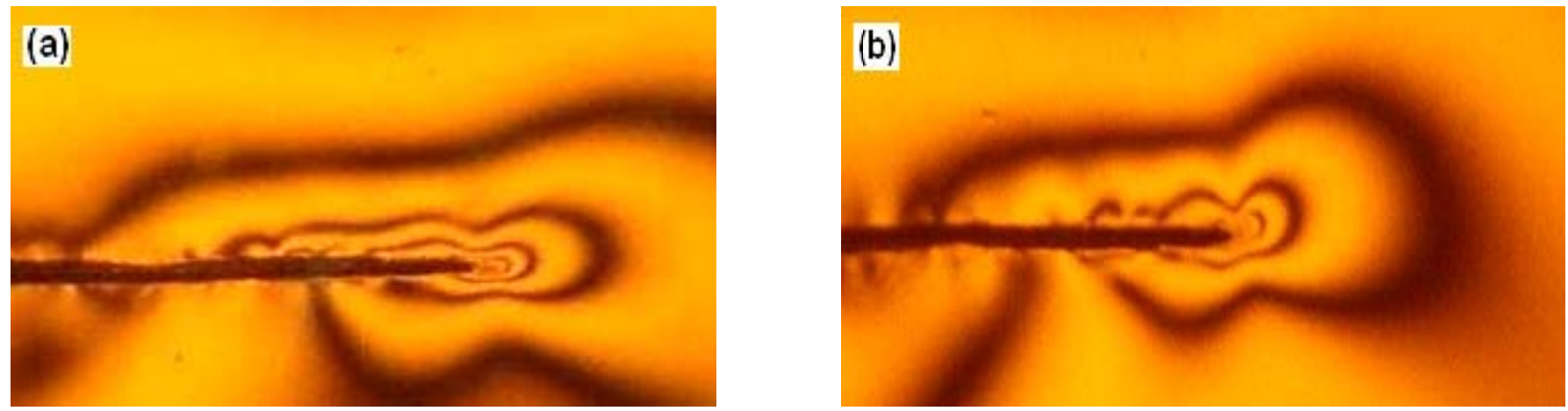

Figure 7. Isochromatic fringes around the crack tips of the disks: a) N-1, b) N-2.

shows the resultant isochromatic fringes around the crack tips for the two disks.

\section{EXPERIMENTAL RESULTS}

As shown in Fig. 7, the obtained photoelastic fringes around the crack tips are asymmetric in both cases. The observed discontinuous loops are in good consistency with the theoretical predictions, and confirm the existence of the T-stress in mode II conditions. This stress term can be quantified by using the common methods for calculating the crack tip parameters, $\mathrm{K}_{\mathrm{I}}, \mathrm{K}_{\mathrm{II}}$, and T.For this aim, the obtained isochromatic fringes were analyzed using a computer code prepared in MATLAB software, and the Image Processing Toolbox was employed to collect some data points from fringe loops of different orders. These data were utilized in another MATLAB program prepared for a full field analysis based on the overdeterministic technique [11]. In this technique, the resultant non-linear equations are numerically solved, and the fitting process involves both the Newton-Raphson me- thod and the method of least squares. Finally, the unknown parameters $\mathrm{K}_{\mathrm{II}}$, and $\mathrm{T}$ were calculated as presented in Tab. 1.

It should be mentioned that $\mathrm{K}_{\mathrm{I}}$ was very small with respect to $\mathrm{K}_{\mathrm{II}}$ in both cases. Hence it could be assumed that the crack tips was subjected to mode II conditions.

\begin{tabular}{|c|c|c|c|}
\cline { 2 - 4 } \multicolumn{1}{c|}{} & \multicolumn{3}{c|}{$\boldsymbol{K}_{\text {II }}[\mathbf{M P a} \sqrt{\mathbf{m ~ m}}]$} \\
\hline Specimen & Experiment & FEM & Error \\
\hline $\mathrm{N}-1$ & 4.34 & 4.71 & $7.9 \%$ \\
\hline $\mathrm{N}-2$ & 4.82 & 5.13 & $6.0 \%$ \\
\hline \multicolumn{4}{|c|}{ T-Stress [MPa] } \\
\hline $\mathrm{N}-1$ & -0.389 & 0.40 & $2.7 \%$ \\
\hline $\mathrm{N}-2$ & -0.262 & 0.27 & $2.9 \%$ \\
\hline
\end{tabular}

Table 1. Experimental results obtained from the Brazilian disks, compared with FEM results [4].

Experimental findings presented in Tab. 1 indicate that the investigated Brazilian disks contain negative values of T-stress in pure mode II condition. In order to validate these results, they are compared with numerical results 


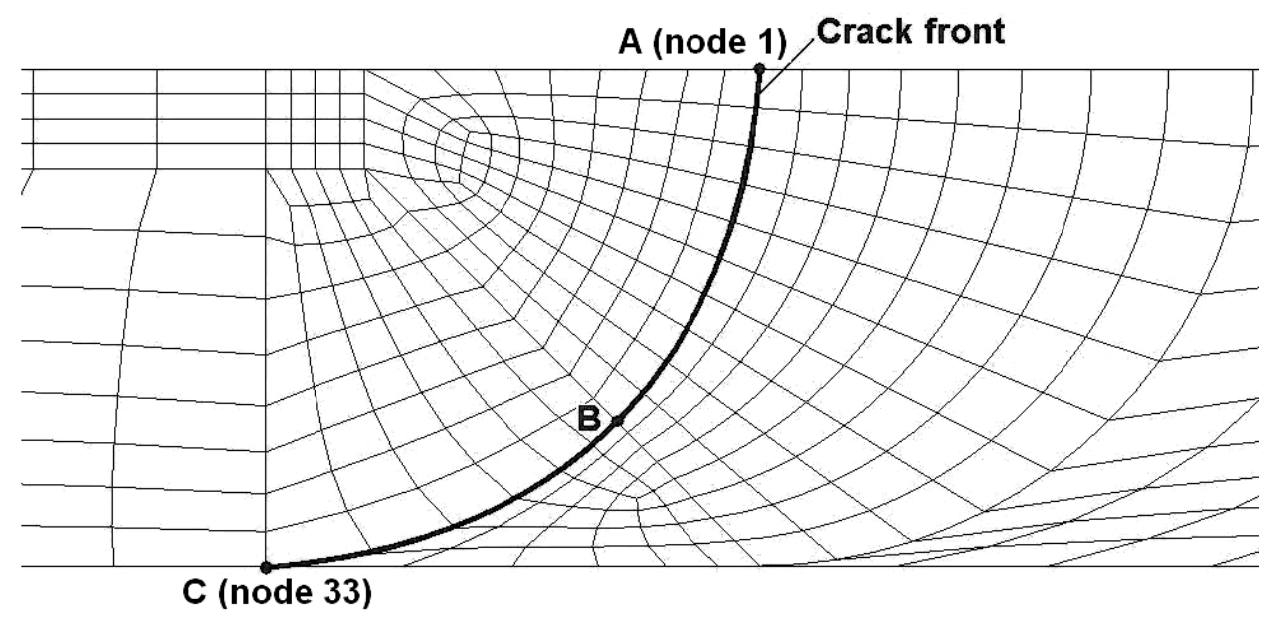

Figure 8. Meshing configuration around the curved crack tip.

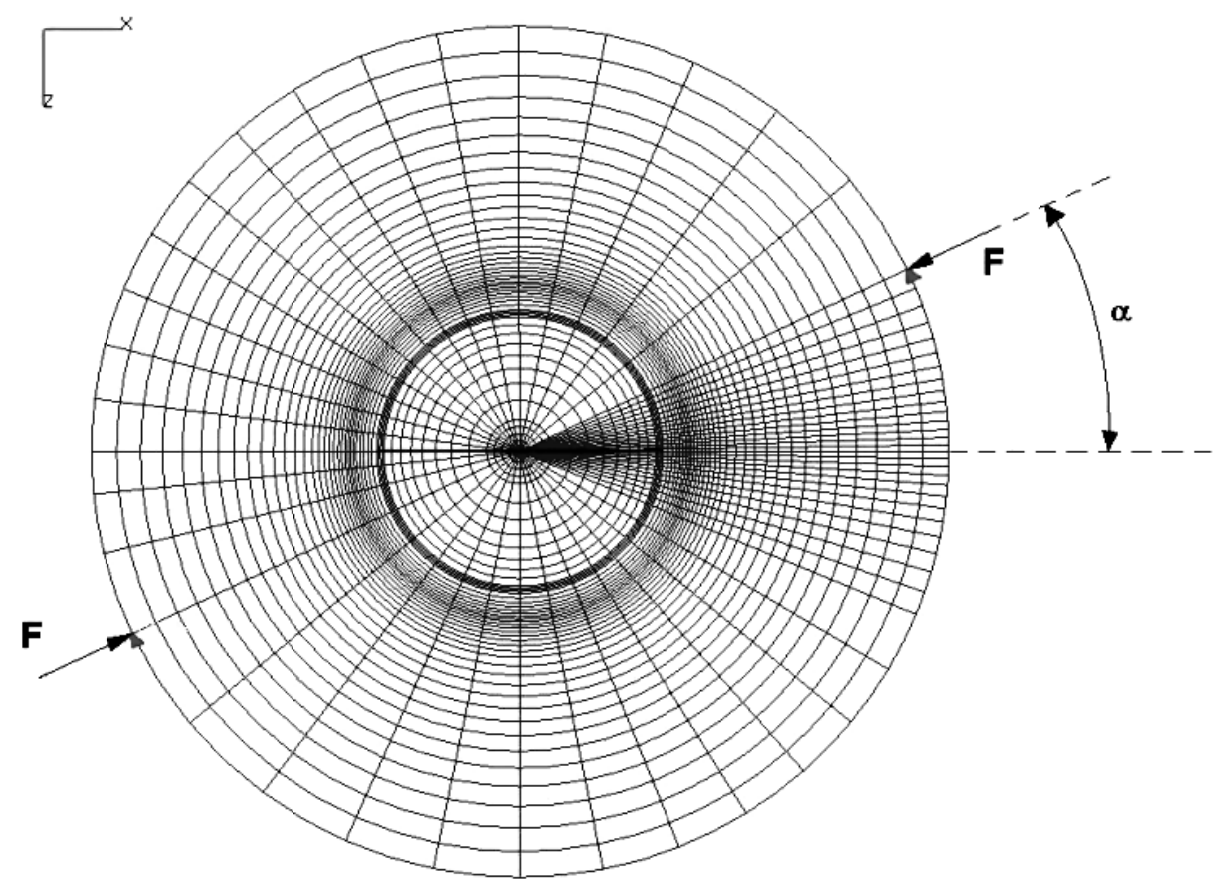

Figure 9. Finite element model with the applied loads and displacements (crack position is indicated in surface with a thicker line).

[4] obtained from FEM analysis (see Tab. 1). It is seen that there is a good agreement between the results from two methods, though there are some minor errors especially in the case of $\mathrm{K}_{\mathrm{II}}$. This problem may be due to the curved crack front through the specimen thickness which was not taken into consideration in the $2 \mathrm{D}$ finite elements models. Hence, the role of crack tip curvature is studied by developing a three dimensional finite element model that is explained in the next section.

\section{INFLUENCE OF THE CURVATURE OF THE CRACK FRONT}

In experimental studies using the photoelasticity, it is possible to analyze the stress condition inside the specimens considering them as 2D-models. In this way, the use of polycarbonate sheet to prepare the cracked specimens allows to investigate only the presence of modes I and II conditions. However, the fringes observed at the polariscope and utilized to calculate the stress intensity factors values, are an integral of the light that describes the stress condition along the thickness of the specimen as well. In this way, the crack tip can also be imposed to out-of-plane stresses that lead to the presence of mode III. With the aim to study the influence of a curvilinear crack front on the stress intensity factors determination, a three dimensional model is developed by using the finite element softwares PATRAN/ABAQUS.

The model schematizes a Brazilian disk similar to the specimens used in experimental part, with radius $\mathrm{R}=120$ $\mathrm{mm}$ and thickness $\mathrm{h}=10 \mathrm{~mm}$. The central crack is placed in correspondence of a diameter, crosses the disk thickness and has a curved front in the form of a circular arc, as shown in Fig. 8. Even if it is not completely correspondent to the real situations, the circular arc increases the curvature effect though the thickness of the crack 


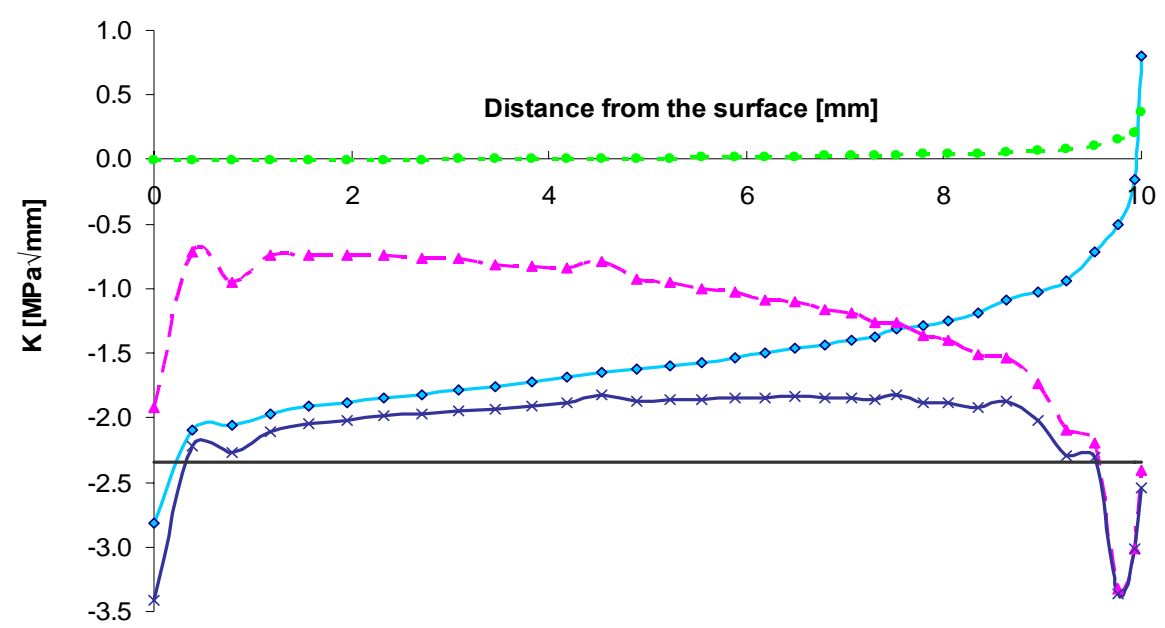

Figure 10. Stress intensity factors along the crack front in function of the depth. $\left(-\bullet-\mathrm{K}_{\mathrm{I}},-\diamond-\mathrm{K}_{\mathrm{II}},-\boldsymbol{\Delta}-\mathrm{K}_{\mathrm{III}},-\mathrm{X}-\mathrm{K}_{\mathrm{IIeq}},-\mathrm{K}_{\mathrm{II}-2 \mathrm{DFEM}}\right.$ [10]).

front and enable to get an indication about the stress intensity factors trend along a non-straight crack front.

Crack curvature radius through the thickness is $10 \mathrm{~mm}$, and the maximum extension of the crack is $2 a=96 \mathrm{~mm}$, indicated with a black thicker line in Fig. 9. The angle $\alpha$ between the direction of application of the compressive force $(\mathrm{F}=375 \mathrm{~N})$ and the crack line is $25.4^{\circ}$. This angle is chosen according to [4] in order to obtain pure mode II on the crack, considering the problem in 2D plane stress state. Displacements of the nodes in which the force is applied, are forced to be in line with the loading direction.

Since the results in terms of $\mathrm{K}_{\mathrm{II}}$ are equivalent considering both the crack tips, only for one of them the mesh has been refined in the circumferential direction. In this way, it is possible to reduce the analysis run time, without loosing accuracy in the final result.

The material of the disk in numerical model is the polycarbonate, with elastic modulus of $\mathrm{E}=2480 \mathrm{MPa}$ and Poisson's ratio $v=0.38$, according to [11]. Solid elements used for the modeling have a shape function of the second order, with a midside node in each edge. This choice allows having more nodes despite a not excessively refined mesh. Moreover, the use of quadratic element is necessary to use the quarter point technique $[17,18]$, that is to move the midside nodes next to the tip to $1 / 4$ of the edge length, which results in a better stress gradient in this area with singularity in the crack tip. Since good results are achievable with these elements even if the singularity is not well modeled on lines other than elements edges [19, 20], no collapsed element is used.

It should be mentioned that to get better results in Jintegral evaluation and consequently on stress intensity factors assessment, mesh directions should always be perpendicular to the crack front [21], avoiding distorted elements. However, the circular shape of the crack front causes a particular pattern for the mesh through the specimen thickness. As shown in Fig. 8, in the upper part form point $\mathrm{A}$ to $\mathrm{B}$, the mesh is more regular and the elements of this region describe the radial directions per- pendicular to the crack front. In the lower part, the arc geometry makes it impossible to draw a regular mesh, and the normal to the crack front is not coincident with the mesh direction.

Numerical results are obtained starting from node 1 corresponding to point $\mathrm{A}$ to node 33 that is point $\mathrm{C}$ in Fig. 8 . Convergence of J-integral and stress intensity results is obtained at the third contour. The trend of stress intensity factors can be graphically observed in Fig. 10 in function of the node distance from the surface. However, the stress intensity factor values obtained near to point $C$ should not be taken into consideration, since elements present a high level of distortion producing low accuracy in the results. Values of the first three nodes are moreover invalid in the discussion, since the third contour integral cannot be calculated and results are infected by the presence of the surface border.

\section{DISCUSSION}

The semi-natural cracks created with a mechanical shock after making brittle the polycarbonate in the liquid nitrogen, have a nonlinear curved tip through the thickness. When the specimen containing such a crack is subjected to mode II loading condition, the global deformation of the crack front is in-plane sliding in $X$-direction. However, considering local coordinate systems $n-t$ moving along the crack tip curve (see Fig. 11), the global displacement of the crack tip points will have two components. The normal component in $n$-direction leads to mode II; and the tangential component in $t$-direction implies that there is also mode III deformations in local view.

In order to find the effect of specimen thickness on the numerical results, they can be compared with the previous results [4] obtained from 2D finite element modeling. For this aim, a new parameter $\mathrm{K}_{\text {Ileq }}$ is defined as:

$K_{\text {Ileq }}=\sqrt{K_{I I}^{2}+K_{I I I}^{2}}$ 


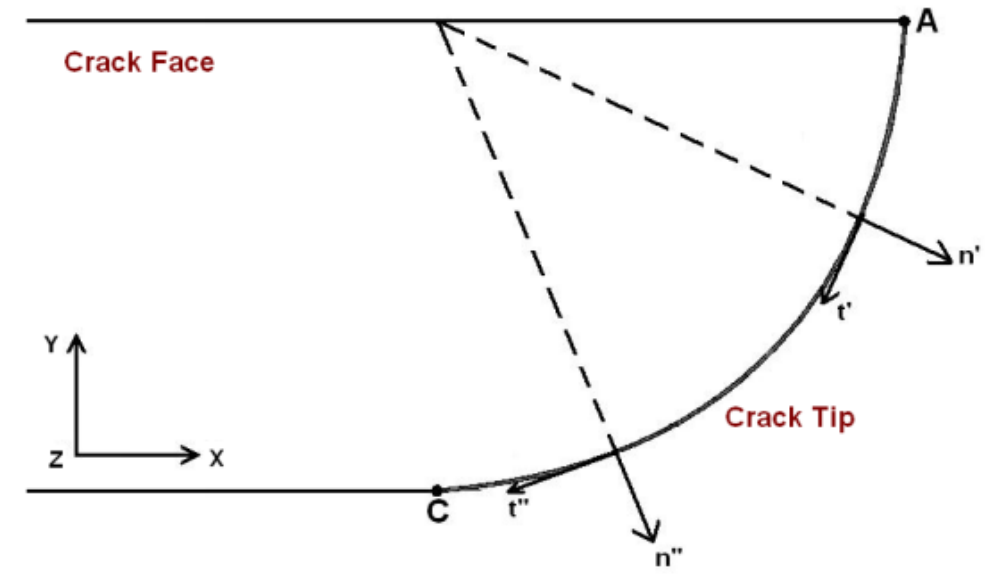

Figure 11. Global $(X-Y)$ and local $(n-t)$ coordinate systems.

which presents the equivalent mode II stress intensity factor in X-direction of the global coordinate system.

It can be noticed from Fig. 10 that $\mathrm{K}_{\mathrm{I}}$ is negligible with respect to $\mathrm{K}_{\mathrm{II}}$ and $\mathrm{K}_{\mathrm{III}}$ for all the considered nodes. Also, $\mathrm{K}_{\mathrm{III}}$ is initially less than $\mathrm{K}_{\mathrm{II}}$. Increasing the curvature that is going toward points $\mathrm{B}$ and $\mathrm{C}, \mathrm{K}_{\mathrm{III}}$ values are increasing and finally becoming more than $\mathrm{K}_{\mathrm{II}}$ values. However, values of $\mathrm{K}_{\text {IIeq }}$ remain about constant, except from surface nodes which are not valid as described before. The observed difference between $\mathrm{K}_{\text {IIeq }}$ and the result of 2D model [4] shows that the thickness of specimen affects the ideal plane stress conditions and leads to some errors in the photoelastic experiment results.

\section{CONCLUSION}

In this research, presence of the T-stress and its effects on the elastic stress field around a mode II crack tip were experimentally studied. Very sharp cracks were created in polycarbonate sheets by using a new method with different steps. The cracks obtained in this way are completely sharp, but the crack tip has a curved shape through the thickness of the specimen. Specimens were cut in the form of centrally cracked Brazilian disk specimens. Photoelastic experiments were conducted on these specimens subjected to mode II loading conditions, to determine from the isochromatic fringe patterns the crack parameters $\mathrm{K}_{\mathrm{I}}, \mathrm{K}_{\mathrm{II}}$, and $\mathrm{T}$ by using computer codes developed with the MATLAB software. Experimental results revealed that the specimens had negative $\mathrm{T}$-stresses in mode II condition.

The experimental results were consistent very well with numerical bidimensional predictions in that the T-stress significantly affects the symmetric shape of the fringe loops, and causes the loops to become asymmetric and discontinuous along the crack edges.

However, there were some minor errors which could be related to the curved shape of the crack front through the specimen thickness. The effect of crack tip curvature on the crack parameters was also investigated by developing a 3D finite element model. The crack front was assumed to be in a circular arc form and, even if it is not com- pletely correspondent to the real situations, aim of this model is to get an indication about the stress intensity factors trend along a non-straight crack front.

The numerical results show that though the global deformation of the crack is in-plane sliding (mode II), in local coordinates there are two shear components which are parallel and perpendicular to the crack front. That is, the crack tip points are subjected to a combination of mode II and mode III deformations. This local mixed mode condition can lead to some errors in the experimental results, which can be a source of difference of experimental results compared to the values of the finite element model.

\section{REFERENCES}

[1] M.L. Williams, "On the Stress Distribution at the Base of a Stationary", Journal of Applied Mechanics, (1957) 109-114.

[2] M.R. Ayatollahi, M. Zakeri, M.M. Hassani, "On the presence of T-Stress in mode II crack problems", 11th International Conference on Fracture, Turin, Italy (2005).

[3] M.R. Ayatollahi, A. Asadkarami A, M. Zakeri, "Finite element evaluation of punch-type crack specimens", International Journal of Pressure Vessels and Piping, 82 (2005) 722-728.

[4] M.R. Ayatollahi, M.R.M. Aliha, "Wide range data for crack tip parameters in two disc-type specimens under mixed mode loading", Computational Materials Science, 38 (2007) 660-670.

[5] B. Cotterell, J.R. Rice, "Slightly curved or kinked cracks", International Journal of Fracture, 16 (1980) 155-169.

[6] M.R. Ayatollahi, H. Abbasi, "Prediction of fracture using a strain based mechanism of crack growth", Building Research Journal, 49 (2001) 167-180.

[7] C. Betegon, J.W. Hancock, "Two-parameter characterization of elastic-plastic crack-tip fields", Journal of Applied Mechanics, 58 (1991) 104-110.

[8] M.R. Ayatollahi, M.J. Pavier, D.J. Smith, "Crack-tip constraint in mode II deformation", International Journal of Fracture, 113 (2002) 153-173. 
[9] K. Ramesh, S. Gupta, A.A. Kelkar, "Evaluation of the stress field parameters in fracture mechanics by photoelastic-revisited", Engineering Fracture Mechanics, 56 (1997) 25-45.

[10] A. Shimamoto, J.H. Nam, T. Himomura, E. Umezaki, "Determination of stress intensity factors in isotropic and anisotropic body by the photoelastic and caustic methods under various load ratios", Key Engineering Materials, 183-187 (2000) 115-120.

[11] J.W. Dally, W.F. Riley, "Experimental Stress Analysis", 3rd edition, McGraw Hill, Singapore (1991).

[12] A.D. Nurse, E.A. Patterson, "Determination of Predominantly Mode II Stress Intensity Factors From Isochromatic Data", Fatigue and Fracture of Engineering Materials and Structures, 16 (1993) 1339-1354.

[13] M.R. Ayatollahi, M. Zakeri, "T-stress Effects on Isochromatic Fringe Patterns in Mode II", International Journal of Fracture, 143 (2007) pp. 189-194.

[14] L. Banks-Sills, M. Arcan, "An edge-cracked Mode II fracture specimen", Experimental Mechanics, 23 (1983) 257-261.
[15] C. Pappalettere, "Annealing Polycarbonate Sheets", Strain, 20 (1984) 179-180.

[16] A. Mondina, "La Fotoelasticità", CUSL (1958).

[17] R.D. Henshell, K.G. Shaw, "Crack tip finite elements are unnecessary", Int. Journal for Numerical Methods in Engineering, 9 (1957) 495-507 (1957).

[18] R.S. Baursom, "On the use of isoparametric finite elements in linear fracture mechanics, Int. Journal for Numerical Methods in Engineering, 10 (1976) 25-37.

[19] L. Banks-Sills, D. Sherman, "On the computation of stress intensity factors for three-dimensional geometries by means of the stiffness derivative and J-integral methods", International Journal of Fracture, 53 (1992) 1-20.

[20] O.C. Zienkiewicz, R.L. Taylor, "The finite element method", Fifth edition, Volume 1: the Basis, Chap. 9, Butterworth-Heinemann Edition (2000).

[21] C. Colombo, M. Guagliano, L. Vergani, "Determinazione numerica dei fattori di intensificazione degli sforzi di cricche caricate in modo misto", Atti del convegno nazionale IGF19, Milano, Italy (2007). 